\title{
Hybrid Game-Based Learning Research at English Class of Primary School $^{*}$
}

\author{
Ximei Qu \\ Zhejiang Open University, Hangzhou, China \\ Email: natasha210@126.com
}

How to cite this paper: Qu, X.M. (2021) Hybrid Game-Based Learning Research at English Class of Primary School. Open Access Library Journal, 8: e8172.

https://doi.org/10.4236/oalib.1108172

Received: November 9, 2021

Accepted: December 5, 2021

Published: December 8, 2021

Copyright (๑) 2021 by author(s) and Open Access Library Inc.

This work is licensed under the Creative Commons Attribution International License (CC BY 4.0).

http://creativecommons.org/licenses/by/4.0/

\begin{abstract}
As ancient tricks enjoyed by most people, game and game-based learning has been long valued by educators. However, there exist some obstacles for the application of educational games in formal school education. For example, some content in games has nothing to do with learning, or the content doesn't match the learning goals. While, in this aspects, "Light games" can do a good job. We find that game-based learning is indeed used by teachers in the classroom nowadays, but most of form is offline, not online. This paper first sorts out the common offline game-based learning methods. Then based on these traditional ways, the paper designs the corresponding online methods: the construction of Digital Library, designing and developing related application, etc. In the end, the paper advocates the concept of "Hybrid Light Game-based Learning".
\end{abstract}

\section{Subject Areas}

Educational Technology

\section{Keywords}

Game-Based Learning, English Class, Primary School, Light Game

\section{Introduction}

As ancient tricks enjoyed by most people, game and game-based learning has been long valued by educators. Vygotsky [1] thinks that learners can use their imagination to satisfy themselves through the games. Chamillard [2] points out that if learners can learn things with simple games, then they can be more active *Supported by 312 Talent Training Project of Zhejiang Open University. 
in the learning. Virous et al. [3] also find that learners can enhance the learning motivation and learning effects when using game-based learning approach. Then what is game-based learning?

On the basis of the previous theories, this paper defines game-based teaching as a teaching method combining effectively games and teaching, entertainment and education while focusing on children's comprehensive development. It plays an indispensable role in arousing children's enthusiasm for learning, developing a right cognitive need and promoting their individual socialization as well as their healthy physical and mental development. Therefore, recently, game-based teaching has been commonly applied in lower-grade education in the primary school in recent years [4]. This article will introduce online and offline gamification methods that are suitable for English class of primary school.

Junjie Shang [5] proposed the concept of "Light Games", and "Light Games" can be expressed in the following formula:

"Light Game" = educational software + intrinsic motivation of mainstream games. Light Game and Serious Game are similar in some aspects, but the concepts are not entirely coincident. Both of them emphasize that entertainment is not the main purpose. But besides this aspect, Light Game particularly emphasizes the close integration of games and courses, and requires that application in teaching should be considered when the Light Game is designed in the beginning.

Through interviews with teachers, we learned that most of them use offline games more, compared with online games. To be sure, many small games are suitable for offline form, such as Drama Performance. However, for others, online form has more advantages:

Firstly, as the digital natives, primary school students are very familiar with online activities; secondly, online games can help teachers save time of preparing real teaching properties and be conducive to sharing resources among teachers; thirdly, the ultimate advantage of online game-based learning is to save a large amount of data which can provide feedback in time to the players as well as teachers and parents. The feedback can be as teaching reference for teachers, and parents can also get to know children's real-time learning situation.

This paper tries to introduce several commonly used offline game-based learning methods and put forward my design about corresponding online game-based learning methods.

\section{Offline Game-Based Learning Method}

The following challenge forms are often used by elementary school teachers in the classroom: speed challenge, reaction challenge, memory challenge, observation challenge, imagination challenge, idea challenge, and so on [6]. This paper mainly introduces several game-based learning methods from three aspects of English learning (pronunciation, vocabulary, sentence/writing): 


\subsection{Pronunciation}

Here comes the introduction of the riddles and Hacky Sack.

1) Riddles

The game of riddles has easy rules and easily operated, and students usually take actively part in it. The game can help train students' listening and speaking ability, develop intelligence and promote strategic thinking. For example, the following two riddles are designed according to the specific meaning and pronunciation of the letters:

What letter is a kind of animal?

What letter is a kind of drink?

In this game, students need quickly match the pronunciation of 26 letters with that of a certain animal or drink, which can help review alphabet.

2) Hacky Sack

This game helps exercise the pronunciation or translation of words between Chinese and English. In this game, teachers need to prepare cards with English words being just learned in advance and post them on the blackboard at class. The students stand in a line and take turns to throw the sandbags to the cards. If students throw at words successfully, they need to read the chosen word or translate it according to the teachers' requirement. If the students couldn't hit any card or give the right answer, they need to stand back to the end of the line until they succeed [7].

\subsection{Vocabulary}

About vocabulary, three games are to be introduced:

1) Word Riddle

The riddles are mainly designed according to the pronunciation, spelling and meaning of the English word. Teachers need to choose appropriate riddles, considering the students' vocabulary.

For example: Which word has three "a" $s$ and two " $n$ " $s$ in it?

2) Word competition

In this game, the teacher puts forward an English letter, and then the students need to speak as more as English words beginning with the given letter. If necessary, teachers can limit the categories of words. Of course, student giving the most number of correct words win.

3) Making new words

This is a very classic game. This game has many forms of operation. For example, the teacher prepares 78 cards, writing one letter in each card, that is to say 26 letters occur three times repeatedly, and then put them into a box. Students take 15 cards from the box every time, and make different words using these 15 letters. In a limited period of time, the students giving the most number of words win.

For example, A B C D E F H I M O P S T V W. If students take these 15 letters, they can make the following words: we. Stop. Me. Face. Mop. Have. Fact. 
Fat. Map. Tea. Pea. Fast. Most. Hi. Steam. Eat. Team. Pop. Pat. Meat. Past...

\subsection{Sentence/Writing}

\section{1) Survey Task Game}

This kind of game has inquiry value. Letting the students carry out the investigation task using English can not only improve the students' ability of English application, but also develop the students' ability of analyzing and solving problems. But for the elementary school students, they have limited knowledge and inquiry ability, so the teacher should design some easy topics.

For example, after learning words about fruits, the teacher can require students to investigate the proportion of the most favorite fruits. The whole class is divided into several groups. Each group makes a table with students' names and words about fruits in English, such as peach, grape, apple and so on. Students in the group investigate the situation of their favorite fruits using the sentence like "What is your favorite fruit", and then get the promotion. Students need to use English when reporting as well.

About this kind of investigating game, the following will not introduce online form. Because we think that offline form is more suitable for this kind of game.

2) Role Play

Role Play is a game that is very suitable for English learning. English is a communication tool in essence. Making a student play a role to stimulate the real situation communicating using English is a quick way to improve English. It is a kind of situational teaching method to help students get into the situation quickly. In the English textbook, there are many dialogues that are suitable to use Role Play.

\section{Online Game-Based Learning}

In China, the class in primary school is generally 40 - 45 minutes long. But some researches show that the children's continuous attention time is not more than 30 minutes, and the younger children are, the shorter the time of their continuous attention is. Adding some online games they are interested in can help attract their attention [8].

According to the above offline game-based learning method, this article will provide the design of the online form of game-based learning. In order to more clearly show the corresponding relationship between offline game-based learning and online game-based learning, the article makes Table 1. Following the table, the article will introduce the online game-based learning in detail.

1) Building Resource Database

We can build a riddle database that is made of many categories, such as pronunciation class, vocabulary class.

In the pronunciation class which is made of many categories as well. Such as, alphabet, then the following two examples can be put into this part:

What letter is a kind of animal? 
Table 1. Corresponding relationship between offline and online game-based learning.

\begin{tabular}{ccc}
\hline Aspects & Offline Game-based Learning & Online Game-based Learning \\
\hline Pronunciation & Riddles & Resource Database \\
Hacky Sack & Online "Hacky Sack" \\
\hline Vocabulary & Word Riddle & Resource Libraries \\
& Word competition & \\
Sentence/Writing & Making new words & \\
& Survey Task Game & StoryMaking \\
\hline
\end{tabular}

What letter is a kind of animal drink?

2) Online "Hacky Sack"

We want to design a teaching software, and the main interface of the game is grid with 9 English words which could not be seen. Only when the button of "start" is pressed, one of these words can be displayed randomly. According to the teaching objectives, teachers can require students to pronounce the word, or do the translation exercises between Chinese and English.

This game can be used for pronunciation, and translation. The software needs to support the function that teachers can update the words in the background. That is to say, this game is mainly to provide a platform for teachers, and can be used in different stages of teaching. Teachers only need to input different words in different stages.

3) StoryMaking

According to the game "Role Play" mentioned in the previous paper, if it is online, I wish to develop such an application. Like RPGMaker, the software can provide some different scenes and some animated characters. After the teacher provides a theme or topic, students can design different scenes and different animated characters to make a story. In the story, the asides and dialogues need to be finished using English. The software can generate the story to a video directly.

This game can help teachers practice the concept of making homework become "homeplay". Teachers can ask students to make a story based on the new words and new topic learnt at class to be their homework. If the homework is required before the class, then it becomes the flipped classroom. The students need to learn the new words and make a story. Then at class, the teachers can assess the video. What is more, teachers can view students' video stories after students finish their stories.

It is important that these data are not only retained, but also timely feedback to the players, teachers and parents.

\section{Conclusions and Future Research}

In this paper, the design of game-based learning is suitable to Chinese class in 
some way. To be sure, offline game-based learning method has many advantages, such as Drama Performance is fit for the offline form. Therefore, we believe that online and offline should be combined to be used. Like the concept of "Hybrid Learning", we advocate the concept of "Hybrid Light Game-based Learning". Teachers can flexibly choose online or offline game teaching methods.

In the future, the online and offline game teaching methods proposed in this paper will be practiced in the class, and the forms of class observation, questionnaire and interviews will be used to test the impact of the use of these methods on students' attention and learning effect.

\section{Conflicts of Interest}

The author declares no conflicts of interest.

\section{References}

[1] Vygotsky, L. (1967) Play and Its Role in the Mental Development of Child. Soviet Psychology, 5, 6-18. https://doi.org/10.2753/RPO1061-040505036

[2] Chamillard, A.T. (2006) Introductory Game Creation: No Programming Required. ACM SIGCSE Bulletin, 38, 515-519. https://doi.org/10.1145/1124706.1121502

[3] Virvou, M., Katsionis, G. and Manos, K. (2005) Combining Software Games with Education: Evaluation of Its Educational Effectiveness. Educational Technology \& Society, 8, 54-65.

[4] Mei, R.Y. (2021) Research on the Practice of Music Game-Based Teaching in the Lower Grades of Primary School. Hubei Normal University, Huangshi.

[5] Shang, J.J., Zhuang, S.Y. and Jiang, Y. (2011) Three Difficulties and Obstacles of Educational Games: Necessary of Developing Light Game. Educational Game, No. $5,65-71$.

[6] Zhang, J. (2014) Application Research of Game-Based Learning in English Class of Primary School. Central China National University, Wuhan.

[7] Yiliyasi, H. (2014) The Application of Game-Based Learning in Chinese Class: Taking an Example of The Sixth Middle School in Bishikaike City of Kyrgyzstan. Xinjiang University, Urumqi.

[8] Pan, Z.Y. (2008) Research of Flash Game-Based Learning Software Design for Children. 